\title{
THE NEURAL SIGNAL FOR THE INTENSITY OF A TACTILE STIMULUS $^{1}$
}

\author{
DENNIS A. POULOS, JUN MEI, ${ }^{2}$ KENNETH W. HORCH, ROBERT P. TUCKETT, JEN YU WEI, \\ M. CARTER CORNWALL, ${ }^{3}$ AND P. R. BURGESS ${ }^{4}$
}

\author{
Department of Anatomy, Albany Medical College, Albany, New York 12208 and Department of Physiology, University of \\ Utah Medical School, Salt Lake City, Utah 84108
}

Received July 29, 1983; Revised December 12, 1983; Accepted January 31, 1984

\begin{abstract}
The effect of indenting the skin at different rates on the perceived intensity of the stimulus was studied by indenting the skin of the fingertip with two triangular waveforms, given as a pair. The subjects were asked to judge which member of the pair was more intense. Perceived intensity was found to increase both with the depth and the speed of the indentation. In contrast, changes in the rate of skin indentation had little influence on perceived skin indentation depth. This suggests that intensity and depth are different attributes of tactile sensibility. Since the skin is viscous, a rapid indentation is more forceful than a slow indentation of the same depth, raising the possibility that perceived intensity is related to stimulus force. Even though intensity judgments were more closely correlated with the force of a stimulus than with the indentation it produced, a rapidly increasing force was felt as more intense than one that increased more slowly but attained the same final magnitude. When mechanoreceptors in the palmar aspect of the monkey's hand were excited with triangular stimuli like those used in the psychophysical studies, their discharge frequency increased with the rate of skin indentation. However, the receptors were distinctly more rate sensitive than the human judgments of stimulus intensity, suggesting that impulse summation in the central nervous system summates (integrates in the mathematical sense) the receptor input so as to enhance, relatively, the perceived intensity of the slower stimuli. Additional evidence in favor of this suggestion came from experiments in which the skin of the fingertip was indented with a stimulus that advanced to a depth of 1 or $2 \mathrm{~mm}$ at a rate of $0.4 \mathrm{~mm} / \mathrm{sec}$, remained steady for $18 \mathrm{sec}$, and then retracted. Ten subjects traced the perceived intensity of these stimuli while they were in progress. During the $1-\mathrm{mm}$ indentation, 8 of the 10 subjects felt the intensity to decline less during the steady phase of the stimulus than did the average discharge of slowly adapting receptors in monkey glabrous skin, and some subjects actually felt an increase in intensity during the stimulus plateau. The discrepancy between perceived intensity and nerve impulse activity was still more pronounced during the $2-\mathrm{mm}$ indentation, when only 1 of the 10 subjects felt a decline in intensity comparable to receptor adaptation. Again, the discrepancy between nerve impulse activity and perceived intensity could be explained by impulse summation in central neural circuitry. To test this possibility further, the fingertips of the same 10 subjects were indented with a stimulus that advanced to a depth of 1 or $2 \mathrm{~mm}$ at a rate of $0.4 \mathrm{~mm} / \mathrm{sec}$, remained steady for 2 to $4 \mathrm{sec}$, and then partially retracted at 0.33 to $0.06 \mathrm{~mm} / \mathrm{sec}$. When the partial retraction amounted to 5 to $30 \%$ of the original excursion, the fingertip was reindented to the same depth, and the sequence began again. Tracings made by 9 of the 10 subjects showed a systematic overestimation error (wind-up) in which they thought the intensity increased during reindentation, although the stimulator actually reindented to the same depth each time. Since cutaneous mechanoreceptors fatigue rather than increase their discharge when repeatedly stimulated, the occurrence of intensity wind-up appears to require a central integrator. However, this neural integration is less pronounced for judgments of intensity than for judgments of skin indentation depth, and intensity integration may be weak or absent in certain subjects.
\end{abstract}

The initial portion of this study investigates whether subjects' reports of the intensity of a stimulus that indents the skin

\footnotetext{
${ }^{1}$ This work was supported by grants from the National Science Foundation and the National Institutes of Health. We thank Barry Evans, John Fisher, Gary Frederickson, Vicki Skelton, and Carol Reeves for their help.

${ }^{2}$ Present address: Department of Physiology, Xian Medical College, Xian, People's Republic of China.

${ }^{3}$ Present address: Department of Physiology, Boston University, 80
}

are influenced by the rate of indentation and compares human intensity judgments with monkey mechanoreceptor discharge when the skin is indented at different rates. Recently we (Burgess et al., 1983b) found that judgments of skin indentation depth are relatively insensitive to changes in the rate at which

\footnotetext{
East Concord Street, Boston, MA 02118.

${ }^{4}$ To whom correspondence should be addressed, at Department of Physiology, University of Utah, 410 Chipeta Way, Salt Lake City, UT 84108.
} 
the skin is indented. Although tactile intensity sensations have been studied under a variety of stimulus conditions for over a century, no investigation appears to have been made of how intensity judgments are influenced by the rate of skin indentation. By comparing the responses of mechanoreceptors in the monkey hand with human intensity judgments when the skin was indented at different rates, we hoped to understand better the controversial issue of how cutaneous mechanoreceptors signal tactile intensity (Kruger and Kenton, 1973; Knibestöl and Vallbo, 1980). We found that the perceived intensity of a stimulus increased with the rate of indentation. Since the same subjects reported that the perceived depth of the indentation did not change much with changes in indentation rate, it would appear that intensity and depth are different attributes of tactile sensibility, each presumably serving a different function (Burgess et al., 1983a). Although intensity judgments were rate sensitive, mechanoreceptors in the monkey hand were still more rate sensitive, suggesting that the central nervous system summates (integrates in the mathematical sense) the receptor input so as to cause a relative enhancement of the perceived intensity of the slower indentations.

'l'he second portion of this study compares intensity judgments with mechanoreceptor discharge during steady skin indentations and during stimuli that, after a partial retraction, reindented to the same depth. The results support the idea that there is an integrator in the central circuitry for the intensity attribute and that it has a shorter time constant than the integrator in the depth circuit.

Thus, the study falls easily into two parts. In the first, changing (triangular) stimuli were used to examine the rate sensitivity of human intensity and indentation depth judgments. Similar stimuli were then used to examine the rate sensitivity of monkey cutaneous mechanoreceptors for comparison with the human intensity judgments. In the second part, changes in perceived intensity during steady indentations and during stimuli that partially retracted and then reindented to the same depth were compared with mechanoreceptor responses to similar stimuli.

\section{Materials and Methods}

\section{Triangular stimuli}

Psychophysical studies. Ten right-handed subjects, ranging in age from 27 to 41 years, were comfortably seated with the right hand in a moulded plasticine support fixed to a table. To immobilize the fingers, a long artificial fingernail was glued to the nail of each finger to be stimulated and embedded in the plasticine. The skin on the palmar aspect of the terminal phalanx of the middle or index finger (fingertip) was indented with an electromagnetic stimulator equipped with a strain gauge that monitored skin displacement and provided a feedback signal for controlling the rate and depth of the excursion. The skin was indented with a flat, circular plastic disc $3.5 \mathrm{~mm}$ in diameter. The moment of skin contact was determined by carefully advancing the stimulator with a micromanipulator until the subject just felt the contact. The stimulator was then advanced another $0.5 \mathrm{~mm}$ to ensure that it remained in secure contact with the skin throughout the test series. The stimuli had a triangular waveform, i.e., the stimulator indented the skin to some preset depth and then immediately retracted at the same rate. The subjects could not see the area of skin stimulated or the moving portions of the stimulator, and operation of the device was silent. The subjects knew nothing of the aims of the experiments, and they were told nothing about their performance until all of the tests had been completed.

The task of the subjects was to compare two skin indentations given 4 to $6 \mathrm{sec}$ apart. One of the indentations in a pair was $1 \mathrm{~mm}$ in amplitude, and the other was $1.5 \mathrm{~mm}$. Sometimes both had the same speed, but usually pairs were given in which one indentation was more rapid than the other. Details about how the stimuli were grouped and randomized have been reported earlier (Burgess et al., 1983b). After eight pairs (trials) had been given (eight trials constituted a "set"), the subjects were allowed to get up and move about the room. The next set was not started until the subjects felt rested, and after each set the stimulator was shifted between the index and middle fingers of the right hand.

Each subject was first asked to judge which indentation in a pair was deeper. The subjects had no trouble understanding this instruction and said they were familiar with indentation depth discriminations from their everyday experience. In addition, several subjects volunteered that they were comfortable with this task because it was related to an easily comprehended stimulus parameter-the excursion of the stimulator tip. Each pair that was to be judged for relative depth was delivered to each subject eight times. After the relative depths of the stimuli had been judged, the entire series of tests was repeated again, but this time the subject was asked to judge which stimulus in a pair was more intense. The first subject that was tested expressed some uncertainty about this discrimination, and so for him and all subsequent subjects an analogy was drawn with vision and audition in the sense that a bright light is more intense than a dim one and a loud sound more intense than a soft one. The subjects were asked to apply these common visual and auditory experiences to the tactile sensations elicited by the mechanical stimulator. Some subjects asked whether this was the same as the force of the stimulus, to which the experimenter replied that he did not know. As in the case of the indentation judgments, each pair to be tested was applied to each subject eight times. For both indentation and intensity, the situation was forced choice; if the two stimuli felt equal, the subject was asked to guess which was deeper or more intense.

In some experiments, measurements were made of the force required to indent the skin at different rates. This was done by attaching a low compliance force transducer to a mechanical driver and indenting the skin with the transducer. The tip of the transducer was $3 \mathrm{~mm}$ in diameter and slightly rounded.

Differences in the performances of the subjects on different pairs were evaluated by casting the data in a $2 \times N$ table and using the $\chi^{2}$ statistic. Comparison of the performances for a given pair to that expected if the subjects felt the two members of the pair as equal was made with the binomial distribution for $p=q=1 / 2$. All statistical tests were double tailed, with a confidence level of 0.01 .

Physiological studies. The same population of mechanoreceptors from the palmar aspect of the monkey's hand was used as in a previous study (Burgess et al., 1983b), where the methods are described in detail. The stimulator for the animal experiments was the same as for the psychophysical studies and again was activated with triangular waveforms. In order to compare the receptor recordings made from monkeys (Macaca mulatta) and the human psychophysical experiments, some decisions had to be made about what the $1.0-$ and $1.5-\mathrm{mm}$ fingertip indentations used in the human studies correspond to for the monkey. A 2-mm excursion from an initial indentation of $0.5 \mathrm{~mm}$ caused a nearly complete indentation of the index or middle fingertips of our smaller human subjects; similarly, a $1.3-\mathrm{mm}$ excursion from an initial indentation of $0.3 \mathrm{~mm}$ produced a nearly complete indentation of the corresponding monkey fingertips. Therefore, in the monkey studies, a maximal excursion of $1.3 \mathrm{~mm}$ was used, starting from a rest indentation of $0.3 \mathrm{~mm}$. A $0.65-\mathrm{mm}$ excursion for the monkeys was assumed to correspond approximately to a 1-mm excursion for humans and a 0.975 $\mathrm{mm}$ excursion for monkeys to a $1.5-\mathrm{mm}$ excursion for humans. The diameter of the disc-shaped stimulating tip was also smaller in the monkey experiments ( 2 rather than $3.5 \mathrm{~mm}$ ). The responses of the receptors to the triangular stimuli were represented by plotting impulse frequency (impulses per second) versus indentation depth (millimeters) during both the indentation and retraction phases of the stimuli.

\section{Plateau and reindentation stimuli}

Psychophysical studies. The procedures were similar to those described in part I. Stimuli 1 or $2 \mathrm{~mm}$ in amplitude were given from an initial (rest) indentation of $0.5 \mathrm{~mm}$. All of the stimuli advanced into the skin at a rate of $0.4 \mathrm{~mm} / \mathrm{sec}$. The same subjects used by Mei et al. (1983) were also used for the present psychophysical tests, and the waveforms for each subject were also the same except that now the subjects were asked to trace their perception of the strength (intensity) of the stimulus rather than its depth. Each waveform to be evaluated was delivered three to six times to the subject's left hand (all the subjects were right-handed), and for each stimulus presentation the subject moved a potentiometer with his right hand to track the perceived intensity of the stimulus. The potentiometer had a pointer which moved along a numbered scale, and the subjects were instructed to call the intensity of the rest indentation zero. Otherwise, they were free to scale as they wished. 
The following statement was read to each subject at the start of the experiment: "The skin of one of your fingertips will be indented in different ways. Your task is to move this pointer along the scale so that the position of the pointer matches your perception of the intensity of the fingertip stimulus. It may help you appreciate what is meant by intensity if you remember that loud sounds are more intense than soft ones and bright lights are more intense than dim ones. You are asked to follow the intensity of the fingertip stimulus with the pointer from the beginning to the end of the stimulus. Call the initial intensity before the stimulus begins zero. Do you have any questions?" The subjects were given two to three trials in the apparatus before actual testing was begun.

The output of the potentiometer that was controlled by the subjects and a signal indicating the position of the stimulator were fed into different channels of a strip chart recorder. The results were analyzed by comparing the actual waveforms with the subjects' representations of their sensations. Differences in the subjects' responses to different stimuli or to different portions of the same stimulus were evaluated with the Wilcoxon matched-pairs signed-ranks test. The criterion for significance was $p<0.01$ (two tailed).

Physiological studies. The same population of slowly adapting glabrous skin receptors (19 SAI and 2 SAII) was used as in an earlier study (Mei et al., 1983). The recordings were made from the median nerves of two pentobarbital-anesthetized monkeys (Macaca mulatta). Trapezoidal waveforms with steady plateau phases were used, like the stimulus in Figure $4 A$. The stimuli were 0.65 or $1.3 \mathrm{~mm}$ in amplitude and were given to the palmar aspect of the monkey's hand from an initial indentation of $0.3 \mathrm{~mm}$ with the same stimulator used for the psychophysical studies. The data presented here are the same as in Mei et al. (1983), where the methods are described more fully. Nerve impulses were recorded on magnetic tape in parallel with a signal indicating the displacement of the stimulator and were later analyzed with a computer.

\section{Results}

\section{Triangular stimuli}

Psychophysical studies. All of the pairs used in this portion of the study had an amplitude ratio of 1.5 (1.5 versus $1 \mathrm{~mm}$ ). In some trials both pair members had a velocity of $0.2 \mathrm{~mm} / \mathrm{sec}$ (speed ratio of 1). These pairs served as controls for those trials in which the pair members had different speeds. In the latter, the slower member of a pair always had a velocity of $0.2 \mathrm{~mm} /$ sec. When the deeper member of a pair was faster, the speed ratio was considered to be greater than 1 ; i.e., when the 1.5 $\mathrm{mm}$ indentation had a speed $16 \mathrm{~mm} / \mathrm{sec}$ and the $1-\mathrm{mm}$ indentation had a speed of $0.2 \mathrm{~mm}$, the speed ratio was 80 . Conversely, when the $1-\mathrm{mm}$ indentation had a speed of $16 \mathrm{~mm} / \mathrm{sec}$ and the $1.5-\mathrm{mm}$ indentation a speed of $0.2 \mathrm{~mm} / \mathrm{sec}$, the speed ratio was considered to be $1 / 80$. Three of the 10 subjects received 7 different pairs of stimuli with speed ratios extending from $1 / 80$ to 80 . The other 7 subjects received only the pair with a speed ratio of $1 / 80$.

The subjects were first asked to judge which member of each pair indented the fingertip more deeply. The results of this discrimination are shown in Figure $1 A$. At all speed ratios the depth judgments were significantly more accurate than chance, and at no speed ratio did the results differ significantly from the judgments made by another group of subjects given the same pairs as part of a larger series of amplitude ratios (Burgess et al., 1983b). Together these results emphasize the relative insensitivity of indentation depth judgments to the speed of the indentation.

The results obtained when the subjects were asked to judge which member of the pair was more intense are shown in Figure $1 B$. The subjects felt these unequal indentations to be about equal in intensity when the speed ratio was $1 / 8$ and the faster indentation to be more intense even though it was shallower at speed ratios of $1 / 20$ and $1 / 80$. Thus, increasing either the depth or the speed of an indentation increased its perceived intensity.
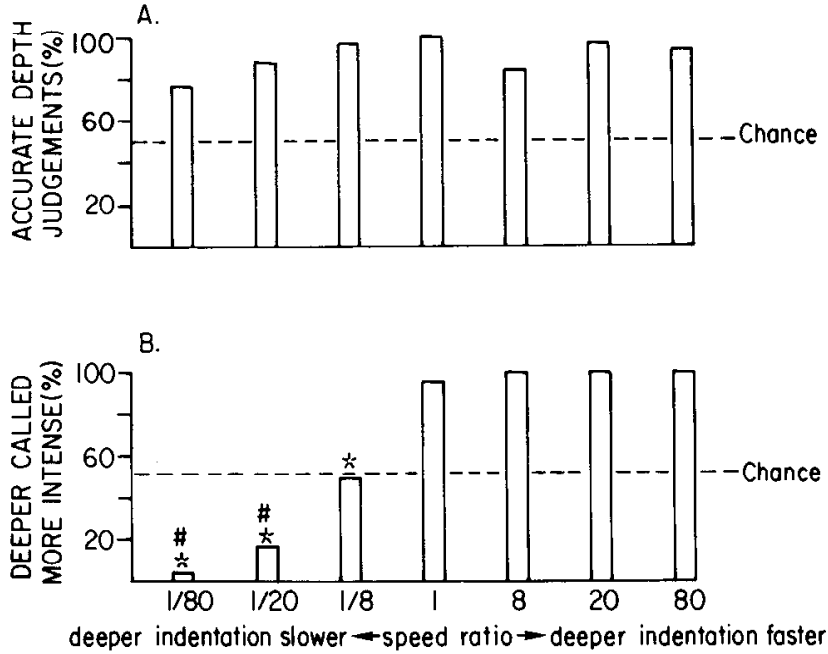

(DEEPER/SHALLOWER)

Figure 1. $A$ indicates the percentage of trials on the fingertip in which the relative depth was correctly judged when comparing amplitudes of 1.5 and $1 \mathrm{~mm}$. The control pairs (speed ratio 1) were equal speed pairs of $0.2 \mathrm{~mm} / \mathrm{sec}$. The slower pair member at the other speed ratios always had an indentation rate of $0.2 \mathrm{~mm} / \mathrm{sec}$. Thus, at a speed ratio of $1 / 80$, the $1.5-\mathrm{mm}$ stimulus indented the skin at $0.2 \mathrm{~mm} / \mathrm{sec}$ and the $1-\mathrm{mm}$ stimulus indented the skin at $16 \mathrm{~mm} / \mathrm{sec}$. At a speed ratio of 80 , the $1-\mathrm{mm}$ stimulus was given at $0.2 \mathrm{~mm} / \mathrm{sec}$ and the $1.5-$ $\mathrm{mm}$ indentation at $16 \mathrm{~mm} / \mathrm{sec}$. Three subjects were tested at speed ratios of $1 / 20$ to $1 / 80$, giving a total of 24 trials at each ratio. Seven additional subjects were included at a speed ratio of $1 / 80$ for a total of 10 subjects and 80 trials at this ratio. $B$ shows the percentage of trials in which the deeper indentation was judged more intense for the same stimulus pairs and subjects shown in $A$. *, Different from controls ( $p$ $<0.01)$. \#, Shallower indentations judged more intense $(p<0.01)$.

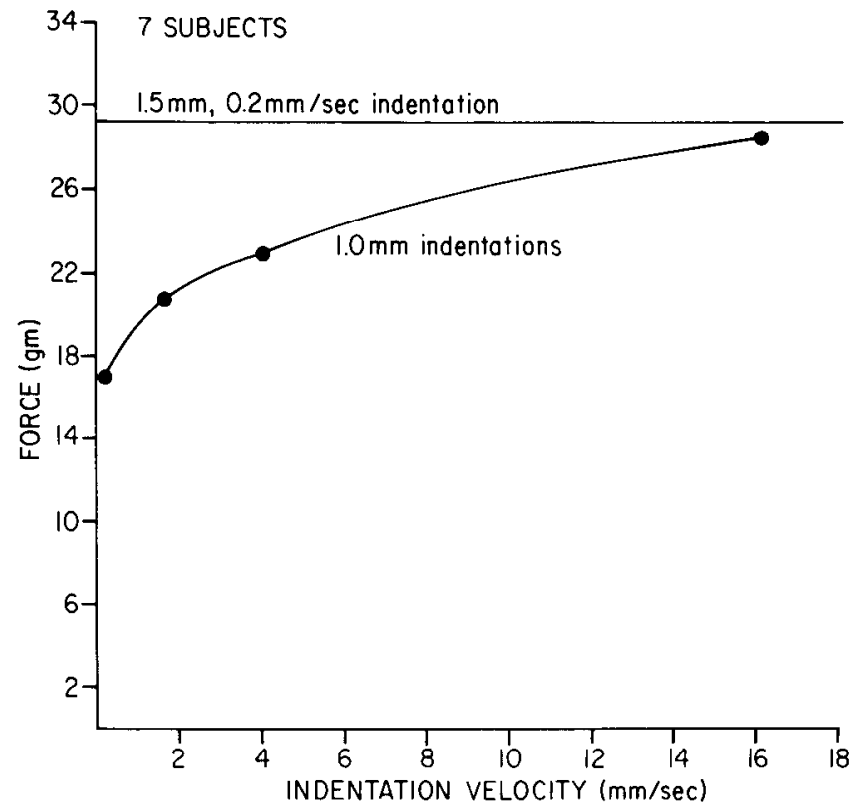

Figure 2. The average peak force produced by a $1.5-\mathrm{mm}$ triangular indentation of the skin with a speed of $0.2 \mathrm{~mm} / \mathrm{sec}$ is shown by the horizontal line. The individual points illustrate the average peak forces generated when the skin was indented $1 \mathrm{~mm}$ at $0.2,1.6,4$, and $16 \mathrm{~mm} /$ sec. The curve was drawn by eye. Measurements were made on seven subjects and have been averaged. The index finger was indented about halfway between the center of the whorl and the fingertip. The displacements were superimposed on a starting indentation of about 0.5 $\mathrm{mm}$, which produced an initial force of 3 to $4 \mathrm{gm}$. 
Intensity judgments might be correlated with stimulus force; since the skin is viscous (as well as elastic; Petit and Galifret, 1978; Pubols, 1982a), a rapid indentation requires more force than a slow indentation of the same depth. Force measurements were made when the skin of the fingertip was indented $1.5 \mathrm{~mm}$ at $0.2 \mathrm{~mm} / \mathrm{sec}$ or indented $1.0 \mathrm{~mm}$ at speeds of $0.2,1.6,4$, and $16 \mathrm{~mm} / \mathrm{sec}$. Although the force required to indent the skin to a given depth increased with speed, it took more force to indent the skin $1.5 \mathrm{~mm}$ at $0.2 \mathrm{~mm} / \mathrm{sec}$ than to indent the skin $1 \mathrm{~mm}$ at $16 \mathrm{~mm} / \mathrm{sec}$. Average values of maximal force for 7 of the 10 subjects are shown in Figure 2. It can be seen that for a 1.0$\mathrm{mm}$ indentation at $4.0 \mathrm{~mm} / \mathrm{sec}$, the maximal force was considerably less than that developed by a $1.5-\mathrm{mm}$ indentation at 0.2 $\mathrm{mm} / \mathrm{sec}$, even though the former was judged more intense in $83 \%$ of the trials (Fig. $1 B$, speed ratio of $1 / 20$ ). When the speed of the $1.0-\mathrm{mm}$ indentation was $16 \mathrm{~mm} / \mathrm{sec}$, the force was still slightly below that for the slow $1.5-\mathrm{mm}$ indentation, although the shallower indentation was judged more intense in $96 \%$ of the trials (Fig. $1 B$, speed ratio of $1 / 80$ ). These results show that intensity judgments are not simply a function of the maximal force generated by an indentation; the rate at which the force increases also influences the judgment.

Physiological studies. There is good evidence that both rapidly and slowly adapting cutaneous mechanoreceptors contribute to tactile intensity sensations (Verrillo, 1966, 1968; Talbot et al.,

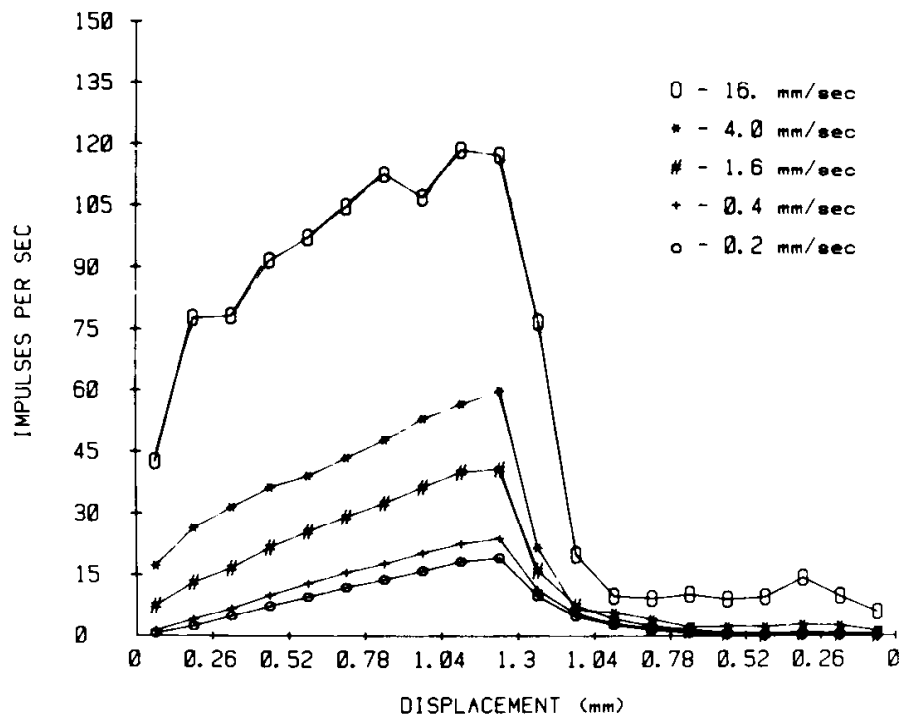

Figure 3. Frequency of discharge versus indentation depth is shown for the entire population of monkey glabrous skin mechanoreceptors (85 rapidly adapting, 78 slowly adapting, and 13 that adapted at an intermediate rate). The stimuli were triangular in form (i.e., they indented and retracted at the same speed and had no plateau phase), and responses are shown for speeds of $0.2,0.4,1.6,4$, and $16 \mathrm{~mm} / \mathrm{sec}$. The frequencies shown are an average for the population and were calculated by dividing the indentation and retraction phases of the stimulus into 10 bins, each representing an increment of $0.13 \mathrm{~mm}$, determining the total number of impulses occurring in each bin, and dividing by the number of receptors in the population and the bin duration. The points are plotted at the centers of the bins; i.e., the point representing the frequency during the increment from 0 to 0.13 $\mathrm{mm}$ is plotted on the horizontal axis halfway between zero and 0.13 $\mathrm{mm}$. Because rapidly adapting receptors varied in rate sensitivity, the number responding increased as the indentation speed increased. $\mathrm{A}$ total of 118 receptors responded at $0.2 \mathrm{~mm} / \mathrm{sec}, 129$ at $0.4 \mathrm{~mm} / \mathrm{sec}, 154$ at $1.6 \mathrm{~mm} / \mathrm{sec}, 167$ at $4 \mathrm{~mm} / \mathrm{sec}$, and 176 at $16 \mathrm{~mm} / \mathrm{sec}$. In computing the average response, those receptors not responding at a particular frequency were, nevertheless, considered to be part of the population; i.e., they contributed zero impulses to each bin.
1968; Harrington and Merzenich, 1970); and in view of the evidence that there is convergence in the neural circuitry for tactile intensity sensations (see von Békésy, 1958; Cholewiak, 1979; Marks, 1979), it seems appropriate to examine the response of the entire population of mechanoreceptors excited from the palmar surface of the monkey hand when relating receptor discharge to intensity judgments. In the discussion to follow, it is assumed that human fingertip indentations of 1 and $1.5 \mathrm{~mm}$ are approximated by indentations of 0.65 and 0.975 $\mathrm{mm}$, respectively, in the monkey fingertip (see "Materials and Methods").

Figure 3 shows a plot of average frequency versus displacement for the entire population of monkey mechanoreceptors (excluding muscle spindle-like receptors) at different indentation speeds. It can be seen that there is an upward slope to these functions so that at any particular velocity the frequency increases with depth. For example, the average discharge of the population increased from 10 to 16 impulses/sec (a $60 \%$ increase) as the depth of the indentation increased from 0.65 to $0.976 \mathrm{~mm}$ at $0.2 \mathrm{~mm} / \mathrm{sec}$. If a higher discharge frequency produces a more intense sensation, this could explain the greater intensity reported by the human subjects for the 1.5$\mathrm{mm}$ as compared with the $1-\mathrm{mm}$ indentation when both stimuli had a velocity of $0.2 \mathrm{~mm} / \mathrm{sec}$. However, a problem arises when applying this interpretation to the pair where the $1-\mathrm{mm}$ indentation had a speed $1.6 \mathrm{~mm} / \mathrm{sec}$ and the $1.5-\mathrm{mm}$ indentation had a speed of $0.2 \mathrm{~mm} / \mathrm{sec}$. The human subjects felt these two stimuli as about equally intense (Fig. $1 B$, speed ratio of $1 / 8$ ). However, examination of the receptor response to the $1.6 \mathrm{~mm}$ / sec and $0.2 \mathrm{~mm} / \mathrm{sec}$ indentations shows that the velocity sensitivity of the receptors is such that the amplitude of the slower indentation must be 4 or more times the indentation depth of the faster stimulus to produce an equivalent level of discharge activity. Therefore, although the 1.0 - and $1.5-\mathrm{mm}$ indentations felt equally intense, the former stimulus provided significantly less neural activity than the latter. The same effect is seen when the discharge of just the slowly adapting (SA) endings is examined (Fig. 8, Burgess et al., 1983b).

\section{Plateau and reindentation stimuli}

In the preceding section, evidence was presented that the perceived depth and intensity of a cutaneous stimulus are different attributes of tactile sensibility. The principal evidence for this distinction is that perceived depth changed relatively little during changes in the rate of skin indentation, whereas perceived intensity increased as the indentation rate increased. Although intensity judgments were more influenced by the rate of skin indentation than depth judgments, they were still less rate sensitive than monkey glabrous skin mechanoreceptors (see preceding section). This raises the possibility that integration might be occurring in the central circuitry for the intensity attribute. Integration in this sense reflects summation of excitation from successive impulses in a train so that a short duration train of high frequency may produce less excitation than a long duration train of lower frequency (see "Discussion"). The experiments to be presented now test for the presence of an integrator.

Psychophysical studies. When subjects were asked to trace the intensity of an indentation like that shown in Figures $4 A$ and $5 A$, some felt little change overall during the steady (plateau) phase of the stimulus (Fig. $4 B$ ), others felt the intensity to increase (Fig. $5 B$ ), and still others felt a decline. The data for all 10 subjects are summarized in Figure 6 . The average change for the group as a whole during an 18-sec plateau was $-5 \%$ for the $1-\mathrm{mm}$ indentation (Fig. $6 A$ ) and $+11 \%$ for the 2$\mathrm{mm}$ indentation (Fig. $6 B$ ). Only one subject (Y. Y. W.) showed 

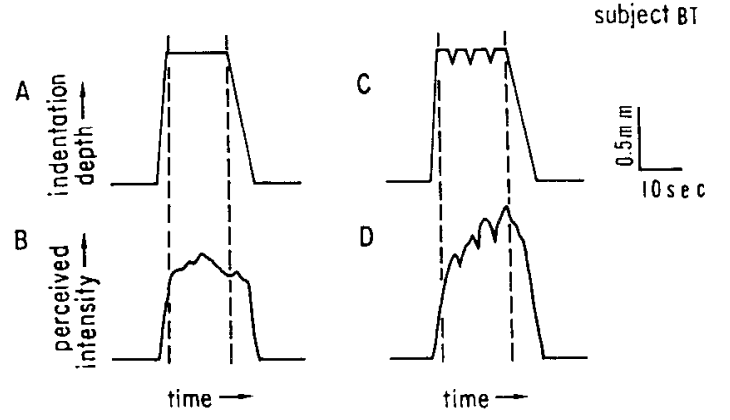

Figure 4. $A$ and $C$ show the $1-\mathrm{mm}$ waveforms actually used to indent the fingertip. $B$ and $D$ show the perceived changes in intensity produced by $A$ and $C$, respectively. $B$ and $D$ have been shifted about $1 \mathrm{sec}$ to the left on the time axis so that they start when the actual waveforms began. The 10 -sec time calibration applies to all of the traces, and the 0.5 -mm depth calibration applies to $A$ and $C$; the ordinate for $B$ and $D$ is in subjective units. $D$ shows a "wind-up" response in which the perceived intensity increased each time the partially retracted stimulator reindented to the same depth.
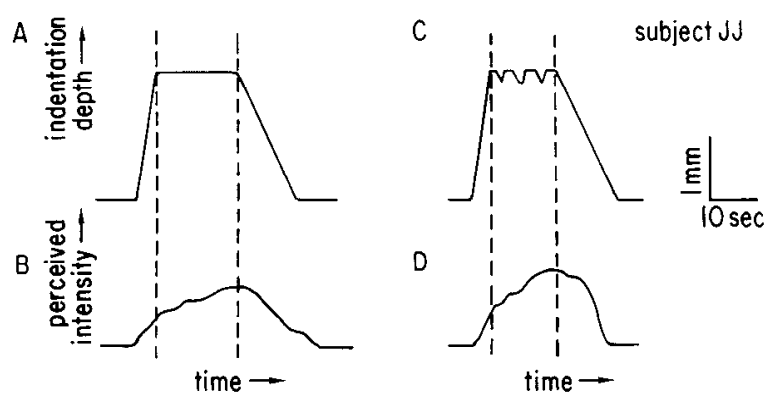

Figure 5. Intensity tracings of another subject, this time to 2-mm indentations, presented as in Figure 4. This subject experienced an unusually large increase in perceived intensity during the plateau waveform $(B)$ as compared with the reindentation waveform $(D)$ during the trials illustrated. Note that the subject did not feel the third reindentation. Other subjects also sometimes missed a reindentation.

an appreciable decline in perceived intensity during the $2-\mathrm{mm}$ indentation (Fig. 6B).

Waveforms of the sort shown in Figures $4 C$ and $5 C$ were also tested. The actual waveforms used varied from subject to subject and were selected for their ability to produce a good overestimation error (wind-up) in perceived indentation depth in a particular subject (Mei et al., 1983); plateau durations ranged from 2 to $4 \mathrm{sec}$, retraction velocities ranged from 0.33 to $0.08 \mathrm{~mm} / \mathrm{sec}$ (wind-up is favored by slow retraction of the stimulator), and the partial retractions ranged from 5 to $30 \%$ of the initial amplitude. The stimulator advanced at a velocity of $0.4 \mathrm{~mm} / \mathrm{sec}$ throughout. Intensity tracings like the ones in Figures $4 D$ and $5 D$ were fairly common (Fig. 7); i.e., the subject felt the intensity to increase as the skin was repeatedly reindented to the same depth. For the subjects as a whole, the average increase over four indentation cycles was $43 \%$ at an excursion of $1 \mathrm{~mm}$ (Fig. $7 A$ ) and $37 \%$ for a $2-\mathrm{mm}$ amplitude (Fig. $7 B)$. Both were significantly greater than zero $(p<0.01)$ and, when combined, were significantly greater than the intensity changes occurring during steady (plateau) waveforms ( $p<$ 0.01 ).

In Figure $5 D$ the subject missed the third reindentation. This occurred quite often; the slow stimulus changes effective in producing wind-up were smoothed at the perceptual level and were hard to follow.

Two subjects (J. F. and O. M.) did not show intensity windup at either 1 or $2 \mathrm{~mm}$ (Fig. 7). It will be recalled that the

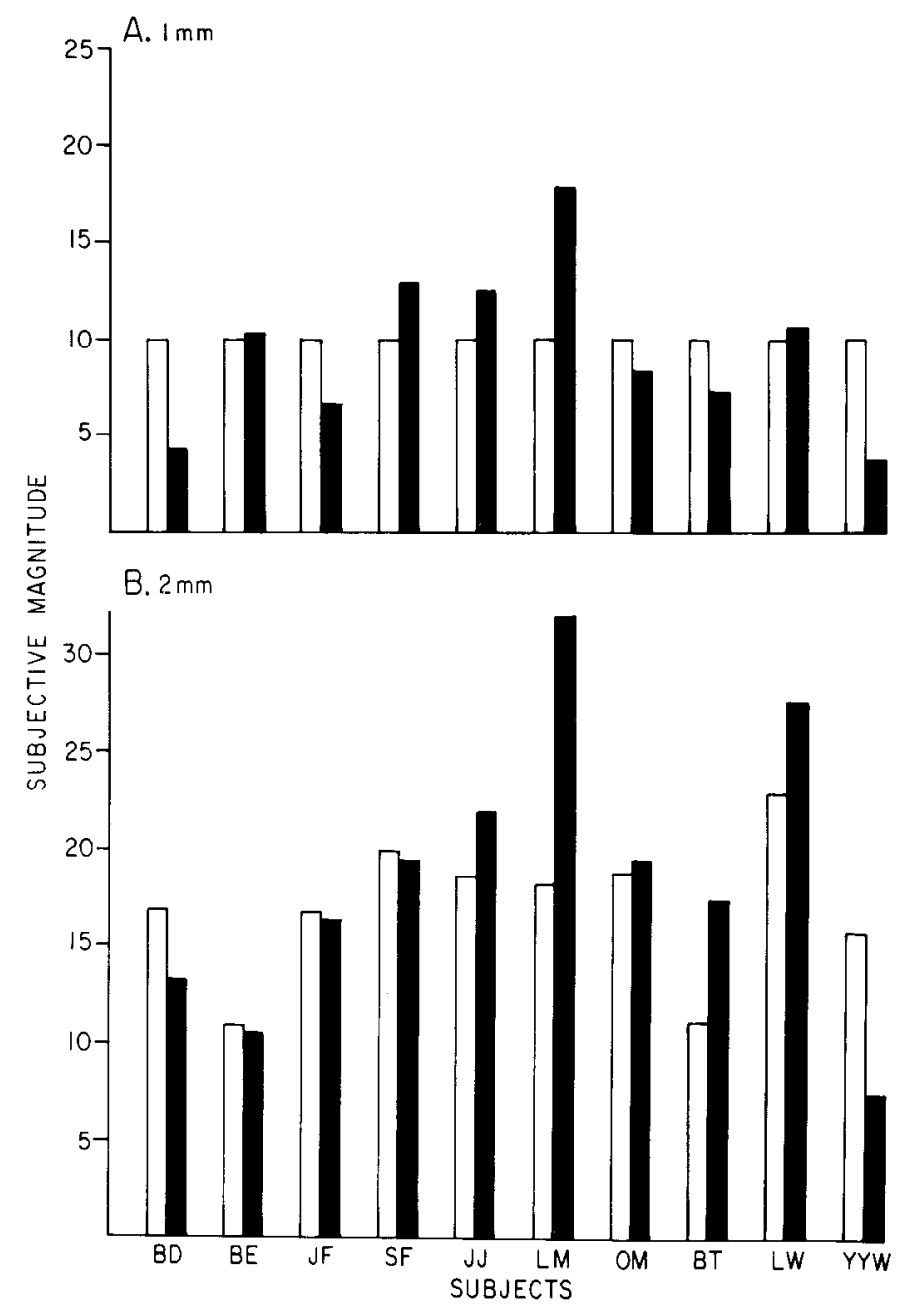

Figure 6. The open bars in $A$ indicate the perceived intensity just after the skin was indented to a depth of $1 \mathrm{~mm}$ at a rate of $0.4 \mathrm{~mm} /$ sec. The solid bars indicate the perceived intensity $18 \mathrm{sec}$ after the first measurement was made. The indentation remained unchanged during this time. To facilitate comparison among subjects, each subject's response to the initial indentation was assigned a value of 10 , and all other responses were scaled relative to this value. $B$ is similar to $A$ except that the depth was $2 \mathrm{~mm}$. The responses were scaled relative to the initial response in $A$. Three to six repetitions of the stimulus were averaged to obtain each of the values shown in $A$ and $B$.

waveforms used to obtain the data in Figure 7 were chosen to give a good wind-up of indentation depth sensations. Depth sensations wind up more readily than do intensity sensations (see "Discussion"), and so even slower retraction velocities were tested on these two subjects to see if intensity wind-up would occur. For both, a retraction velocity of $0.06 \mathrm{~mm} / \mathrm{sec}$ gave windups in the 20 to $30 \%$ range at $2 \mathrm{~mm}$.

It will be noted in Figures 6 and 7 that there was considerable variability in how the subjects scaled the initial intensity at 2 $\mathrm{mm}$. This is probably due at least in part to the fact that the 1 - and 2-mm stimuli were given at different times and that the subjects were not instructed to compare stimuli from different sets of trials but rather to concentrate on any changes in perceived intensity that might occur during a particular stimulus presentation.

Physiological studies. Adaptation is a well known property of cutaneous mechanoreceptors, as verified in Figure 8, which shows the average response of a population of 21 slowly adapt- 
INTENSITY SENSATION WINDUP
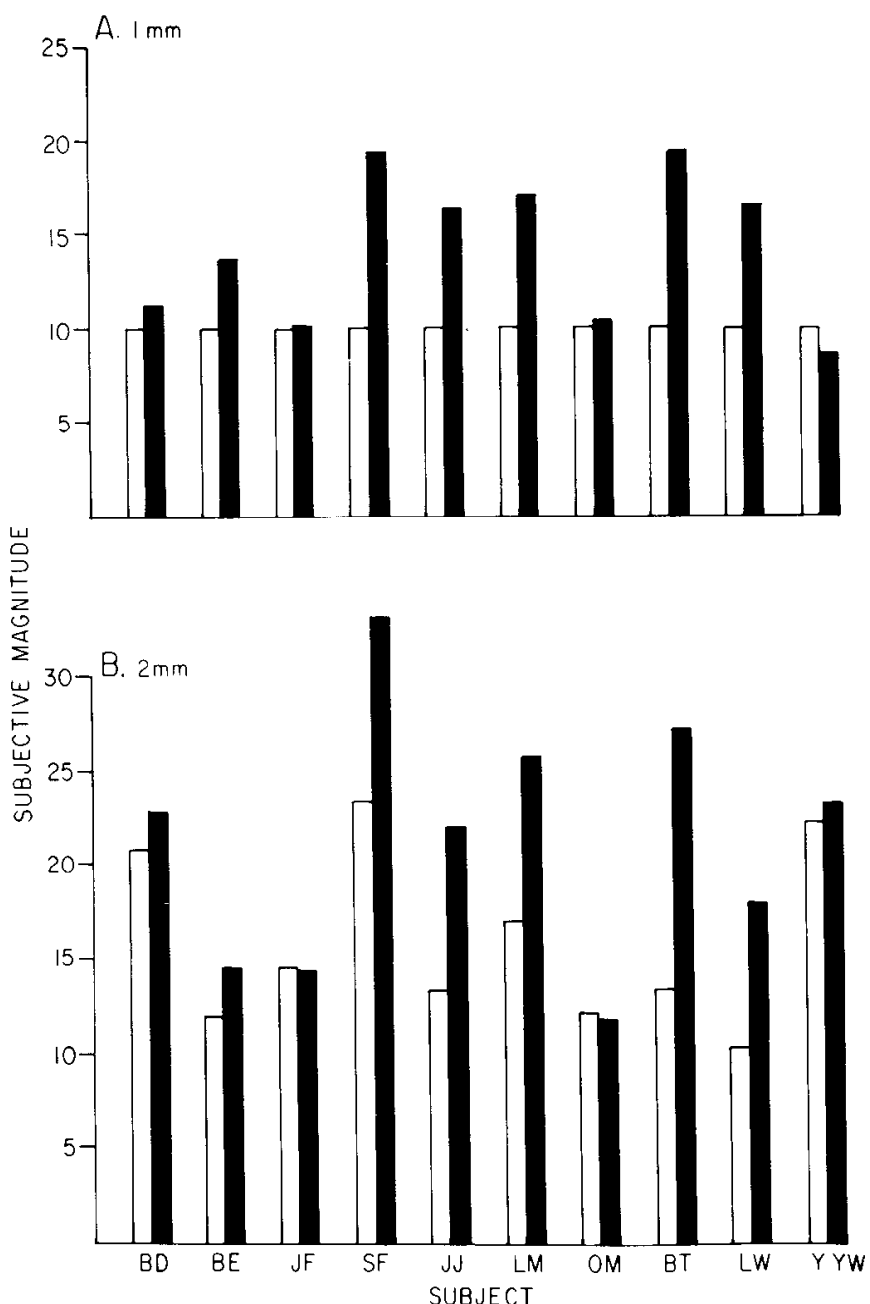

Figure 7. The open bars in $A$ show the perceived intensity just after the skin was indented $1 \mathrm{~mm}$. The stimulator was then partially withdrawn (5 to $30 \%)$ and reindented to the same depth several times. The solid bars show the perceived intensity during the fourth of these sequential indentations. The stimulator advanced at $0.4 \mathrm{~mm} / \mathrm{sec}$, and retraction rates varied from 0.33 to $0.08 \mathrm{~mm} / \mathrm{sec}$. The indentation depth in $B$ was $2 \mathrm{~mm}$. Indentation velocity was $0.4 \mathrm{~mm} / \mathrm{sec}$, and retraction rates varied from 0.29 to $0.11 \mathrm{~mm} / \mathrm{sec}$. The magnitudes in $A$ and $B$ were normalized as in Figure 5 , and three to six repetitions of the stimulus were averaged to obtain each value.

ing glabrous skin mechanoreceptors to $0.65-\mathrm{mm}(A)$ and 1.3$\mathrm{mm}(B)$ trapezoids that indented the skin at $0.4 \mathrm{~mm} / \mathrm{sec}$ and then remained steady for $20 \mathrm{sec}$ before retracting. Adaptation during the plateau phase was determined by comparing the average discharge during the first $2 \mathrm{sec}$ of the plateau with the average discharge during the last $2 \mathrm{sec}$ of the plateau. The decline measured in this way was $45 \%$ in Figure $8 A$ and $48 \%$ in Figure $8 B$. All of the receptors in the population adapted; the most tonic receptor showed a decline of $18 \%$ during the $0.65-\mathrm{mm}$ plateau and a decline of $20 \%$ during the $1.3-\mathrm{mm}$ plateau.

\section{Discussion}

\section{Evidence that intensity and depth are different attributes of tactile sensibility}

Judgments of skin indentation depth and the perceived intensity of a stimulus that indents the skin are different when

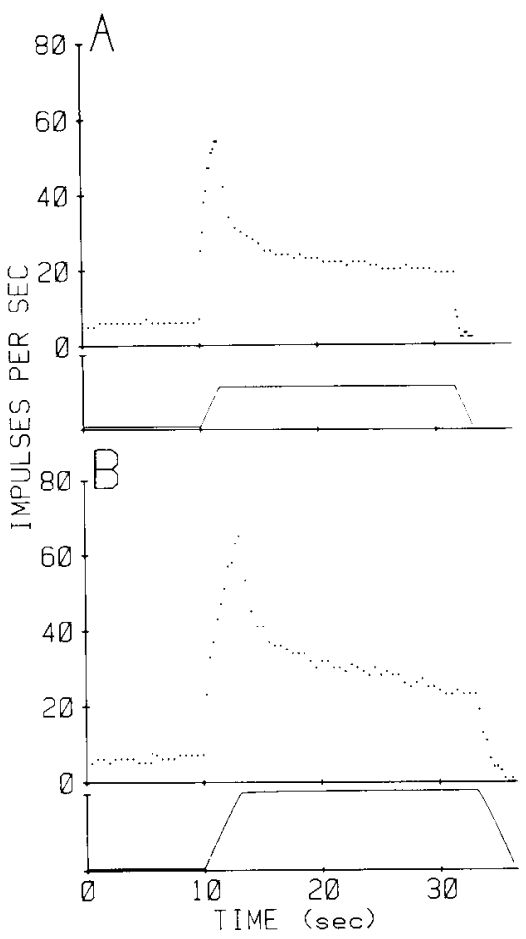

Figure 8 . The average response of 21 slowly adapting receptors is shown to a $0.65-\mathrm{mm}$ trapezoidal stimulus in $A$ and a $1.3-\mathrm{mm}$ stimulus in $B$. The upper trace shows average frequency in impulses per second. The lower trace shows the stimulus. Indentation at $0.4 \mathrm{~mm} / \mathrm{sec}$ was followed by a 20 -sec plateau and then by retraction at $0.4 \mathrm{~mm} / \mathrm{sec}$. To calculate the average response, the rising and falling phases of the stimuli were each divided into time bins of $0.16 \mathrm{sec}$, and the plateaus were divided into bins of $0.5 \mathrm{sec}$. Each receptor was stimulated once by each waveform, and the number of impulses occurring in each time bin was totaled for all of the receptors and divided by the number of receptors in the population and the bin duration. These are the same data as were presented in $A$ and $B$ of Figure 4 in Mei et al. (1983).

the rate of indentation is changed. Depth judgments are not greatly altered by changes in the speed with which the skin is indented, whereas the intensity is felt to increase with increasing speed. The fact that these two perceptions diverge in this fashion indicates that they are different attributes of tactile sensibility (Boring, 1935, 1942; Burgess et al., 1983a, 1984). We are apparently the first to bring forward evidence that indentation depth and intensity are different sensory attributes. One hopes that they have not been confused by subjects participating in earlier experiments which have ostensibly been concerned only with the intensity attribute.

Actually, laboratory apparatus is not required to demonstrate that intensity and indentation depth are different sensory attributes, as the reader can easily verify. A brief puff of air (such as can be obtained by a quick exhalation) directed onto the palm of the hand produces little actual or perceived skin indentation even though the stimulus may feel quite intense. A slow, shallow indentation of the palm made with a small object (such as the rounded eraser on the end of a pencil) produces less intensity that the puff of air but the indentation attribute is, appropriately, distinctly more pronounced. Marked intensity without much sense of altered skin position can also be produced by rapidly applied pressure on the skin where it overlies a bony prominence. Slowly applying pressure on the skin over soft tissues can produce a considerable feeling of indentation without much intensity; i.e., the relationship between perceived skin indentation depth and how strong the stimulus feels varies 
with the firmness of the underlying tissue. Again, the fact that perceived intensity and perceived depth can be made to diverge by suitable manipulations of the stimulus defines them as different sensory attributes (Burgess et al., 1983a).

Since intensity and indentation depth are separate attributes of tactile sensibility, they presumably have different functions. The function of the indentation attribute seems relatively straightforward. It provides fairly reliable information about the extent to which an object indents the skin. Actually, the depth information is sufficiently fine grained that the curvature (profile) of the indented area can usually be ascertained, and this in turn provides information about the curvature of the stimulator face. One can think of the indentation attribute as adding a third dimension to the already well studied awareness of the location of a stimulus on the surface of the body.

We were hopeful that the intensity attribute would monitor the force of the stimulus in a relatively direct way. In past studies of tactile intensity, force has been the stimulus parameter that was usually controlled (see Sherrington (1900) for an able review of early work and Holway and Crozier (1937) and Stevens and Mack (1959) for more recent examples), although the effect of changing the rate of force development on suprathreshold intensity judgments was not studied. More recently, skin indentation depth has been the parameter against which subjects have rated their intensity sensations (Harrington and Merzenrich, 1970; Knibestöl and Vallbo, 1980). In the present experiments, although intensity judgments were found to parallel indentation force more closely than indentation depth, perceived intensity increased more rapidly than did the maximal force when the speed of the indentation increased. The first subject we tested suggested that the perceived intensity of a stimulus is proportional to its ability to attract one's attention. Other subjects agreed. Perhaps one of the functions of the intensity attribute is to alert an animal to stimuli that are rapid or forceful.

\section{The neural signal for the inlensity of a tactile stimulus}

The concept that the central circuit for intensity judgments is linear. An interesting question in sensory physiology is the extent to which the central nervous system operates linearly on its inputs. (Linear in this context means that $\Delta Y / \Delta X$ is a constant for all $X$ and $\Delta X$, where $\Delta Y$ is the change in the output of a central circuit in response to a change $(\Delta X)$ in the input to the circuit measured in impulses per sec.) If the central circuits are linear, the input-output characteristics of the system are set by the receptors.

The intuitively appealing notion that a stimulus will be felt as more intense if it produces a larger afferent input has a long history (Sherrington, 1900). When single unit recording became possible, it was shown that increasingly intense sensations could not be accounted for by larger action potentials, but rather it was suggested that the number of impulses in a given time period determined the perceived intensity of the stimulus (Adrian and Zotterman, 1926a). This idea gained further support from the demonstration that the input-output functions of individual peripheral mechanoreceptors resembled perceptual input-output functions for intensity in the sense that, when stimuli of increasing strength were given, both inputoutput functions increased relatively rapidly at first and then more slowly as the stimulus became stronger (Matthews, 1931). In this historical context it is perhaps not surprising that the central circuits giving rise to intensity sensations have been proposed to operate linearly such that the input-output characteristics of intensity sensations are set by the receptors (Mountcastle, 1967).

Evidence suggesting that the central intensity circuit may not be linear. The present experiments provide three lines of evidence that the central circuits for intensity discriminations are not linear: (1) mechanoreceptors in the monkey hand showed greater rate sensitivity than human intensity judgments; (2) intensity sensations were generally better sustained than mechanoreceptor discharge during steady skin indentations; and (3) intensity sensations tended to increase when the skin was reindented to the same depth, whereas mechanoreceptor discharge would be expected to decline due to fatigue. Each of these will be discussed in turn.

The data reported in part I above indicate that the tactile intensity sensations of our human subjects were less rate sensitive than the mechanoreceptors in the hands of the monkeys we studied. Since the work of Knibestöl $(1973,1975)$ has shown that the mechanoreceptors of humans and monkeys are similar, our data suggest that there is some mechanism within the human central nervous system that produces a relative enhancement of the perceived intensity of the slower indentations. Integration (in the mathematical sense) of the receptor input by the central neural circuits involved in intensity judgments would produce an effect of this sort.

In part II it is reported that perceived intensity typically declines less during a steady indentation than does the discharge of cutaneous mechanoreceptors. Eight of the 10 subjects tested showed less adaptation during a 1-mm plateau than did the average response of the slowly adapting mechanoreceptors in our sample from monkey glabrous skin. When the amplitude of the plateau was increased to $2 \mathrm{~mm}, 9$ of the 10 subjects showed less adaptation than the monkey receptors (Figs. 6 and 8). Some subjects actually felt the intensity to increase during the plateau phases of both the 1 - and 2 -mm stimuli (Fig. 6). At longer time intervals ( $>60 \mathrm{sec}$ ), all subjects felt the intensity to decline (P. R. Burgess, unpublished observations), as would be expected from earlier studies on hairy skin (Zigler, 1932; Crook and Crook, 1935; Horch et al., 1975), although the sensation persists on the fingertips for considerably longer than on hairy skin (Burgess et al., 1983b; Mei et al., 1983).

Slowly adapting receptors in human glabrous skin are similar to those in monkey (Knibestöl, 1975); they adapt to a constant indentation, as do all cutaneous mechanoreceptors that have been examined in vertebrate animals. In our view, the persistence of perceived intensity despite a declining receptor signal can be most easily explained by assuming that there is an integrator in the central neural circuitry that gives rise to tactile intensity sensations.

The third line of evidence that the central circuits for intensity are not linear comes from the intensity wind-up that occurs when the skin is reindented to the same depth after a slow partial retraction of the stimulator (see part II above). Windup is unlikely to occur at the receptor level because cutaneous mechanoreceptors show decreasing responsiveness to repeated stimuli (Adrian and Zotterman, 1926b; Bessou et al., 1971; Barker et al., 1982; Pubols, 1982b). Preliminary experiments of our own have shown that mechanoreceptors in the monkey hand do not wind up when reindented with stimuli like those used in the psychophysical studies (R. P. Tuckett, J. Y. Wei, and P. R. Burgess, unpublished observations). Thus, wind-up of perceived intensity appears to require the presence of a central neural integrator since alternative explanations are lacking.

In summary, these three lines of evidence combine to give clear support for the presence of neural integration in the central circuitry that mediates intensity sensations. However, this integration process is not so pronounced for intensity as for skin indentation depth judgments (Burgess et al., 1983b; Mei et al., 1983 and below) and may be weak or absent in some subjects.

Some properties of a neural integrator and previous reports of their presence in somatic sensation

An integrator functions through persistence of excitation. In neural terms, this means that the excitatory effect of an arriving 
impulse sums with the excitation remaining from preceding impulses and that this excitation persists even though the integrator neuron(s) has generated an action potential. One way that summation could occur in the tactile intensity integrator (and other neural integrators) is by the addition of excitatory postsynaptic potentials, each of which is declining more or less exponentially (temporal summation; Eccles, 1957). Alternatively, integration could occur as a consequence of reexcitation by circulating activity in interneuron pools. Such circulating activity would presumably decline with time, and so in either case the integrator would be "leaky" (i.e., the depolarization of the integrator neuron would decay in the absence of input), which is consistent with the observation that strong taclile aftersensations rarely last more than a few seconds.

Although an integrator has not been suggested previously for tactile intensity sensations, integrators that leak to varying degrees are well documented in somatic sensation. Price (1972) has shown that second pain winds up and Jarvilehto (1973) and Molinari et al (1977) have presented evidence for an integrator in the central circuits giving rise to thermal sensations. It is known that spinal circuits are capable of producing persistent excitation (Price et al., 1978), and we have taken the term wind-up from Mendell and Wall (1965), who showed that repeated sural $\mathrm{C}$ fiber volleys of fixed size caused a progressively increasing discharge of certain spinal neurons. However, these spinal systems seem more concerned with "irritating" than with tactile sensations (Melzack and Eisenberg, 1968; Price et al., 1978).

Models of leaky integrators with exponential decay can be constructed easily. The model discussed below uses temporal summation of excitatory postsynaptic potentials (EPSPs), but the same principles would apply to integration due to circulating activity in interneuron pools. Input-output nonlinearities due to neural integration are casiest to demonstrate experimen tally if both the duration of the stimuli (or the time at which the judgment is made during a continuous stimulus) and the strength of the stimuli are allowed to vary. This is because a brief high frequency discharge may charge the integrator less than a lower frequency discharge of longer duration and vice versa. In fact, as long as the input frequency is high enough to exceed the integrator decay rate, increasing the duration of the input will increase the charge on the integrator even though the input frequency is unchanged. This effect would be countered by the tendency for EPSP size to decrease with increasing depolarization (Eccles, 1957), and some increase in the rate of EPSP decay with increasing depolarization would be necessary to prevent the depolarization from building up indefinitely.

There is a recent report of a pronounced lack of correlation between the discharge of individual mechanoreceptors and perceived intensity when the skin of the hand is deeply indented (Knibestöl and Vallbo, 1980). The intensity sensation continued to increase with increasing indentation depth even though the discharge of the mechanoreceptors directly under the stimulator was increasing relatively little (i.e., they were saturating). The stimuli were rated for intensity at a constant interval after stimulus onset, and under these conditions it is difficult to predict whether an integrator would produce a nonlinearity of the type described. Alternatively, the results might be explained by progressive lateral recruitment of receptors with increasing indentation depth which compensates for the saturating receptors under the stimulator.

\section{Comparison of the neural integrators for intensity and indentation depth judgments}

There is evidence that an integrator is present also in the central neural circuitry that senses the depth of a skin indentation (Burgess et al., 1983b; Mei et al., 1983). When the intensity and depth sensations evoked by the same stimulus waveforms are compared, it can be seen that the integrator in the depth circuit has a longer time constant (a slower leak) than the integrator in the intensity circuit: (1) intensity judgments decrease more than depth judgments when skin indentation rate decreases (Burgess et al., 1983b; the present study; see also Burgess et al., 1983a); (2) intensity is less likely to build up during a steady indentation; and (3) intensity shows less wind-up than depth (Mei et al., 1983; the present study). The reason for the differing time constants is unknown.

\section{References}

Adrian, E. D., and Y. Zotterman (1926a) The impulses produced by sensory nerve endings. Part 2 . The response of a single end organ. J. Physiol. (Lond.) 61: 151-171.

Adrian, E. D., and Y. Zotterman (1926b) The impulses produced by sensory nerve endings. Part 3. Impulses set up by touch and pressure. J. Physiol. (Lond.) 61: 465-483.

Barker, D. J., P. D. Shepard, and K. L. McDermott (1982) Fatigue in cat facial mechanoreceptors. Neurosci. Lett. 30: 117-122.

Bessou, P., P. R. Burgess, E. R. Perl, and C. B. Taylor (1971) Dynamic properties of mechanoreceptors with unmyelinated (c) fibers. J. Neurophysiol. 34: 116-131.

Boring, E. G. (1935) The relation of the attributes of sensation to the dimensions of the stimulus. Philos. Sci. 2: 236-245.

Boring, E. G. (1942) Sensation and Perception in the History of Experimental Psychology, Appleton-Century, New York.

Burgess, P. R., K. W. Horch, and R. P. Tuckett (1983a) Boring's formulation: A scheme for identifying functional neuron groups in a sensory system. Fed. Proc. 42: 2521-2527.

Burgess, P. R., J. Mei, R. P. Tuckett, K. W. Horch, C. M. Ballinger, and D. A. Poulos (1983b) The neural signal for skin indentation depth. I. Changing indentations. J. Neurosci. 3: 1572-1585.

Burgess, P. R., R. P. Tuckett, and K. W. Horch (1984) Topographic and nontopographic mapping of spatial sensory information. Predictions from Boring's formulation. In Comparative Physiology of Sensory Systems, L. Bolis and R. D. Keynes, Cambridge University Press, Cambridge, England, in press.

Cholewiak, R. W. (1979) Spatial factors in the perceived intensity of vibrotactile patterns. Sensory Processes 3: 141-156.

Crook, M. N., and H. Crook (1935) Adaptation to cutaneous pressure. Am. J. Psychol. 47: 301-308.

Eccles, J. C. (1957) The Physiology of Nerve Cells, The Johns Hopkins Press, Baltimore.

Harrington, T., and M. M. Merzenich (1970) Neural coding in the sense of touch: Human sensations of skin indentation compared with the response of slowly adapting mechanoreceptive afferents innervating the hairy skin in monkeys. Exp. Brain Res. 10: 251-264.

Holway, A. H., and W. J. Crozier (1937) Differential sensitivity for somesthetic pressure. Psychol. Rec. 1: 170-176.

Horch, K. W., F. J. Clark, and P. R. Burgess (1975) Awareness of knee joint angle under static conditions. J. Neurophysiol. 38: 1436-1447.

Jarvilehto, T. (1973) Neural coding in the temperature sense. Human reactions to temperature changes as compared with activity in single peripheral cold fibers in the cat. Ann. Sci. Fenn. B 184: 1-71.

Knibestöl, M. (1973) Stimulus-response functions of rapidly adapting mechanoreceptors in the human glabrous skin area. J. Physiol. (Lond.) 232: 427-452.

Knibestöl, M. (1975) Stimulus-response functions of slowly adapting mechanoreceptors in the human glabrous skin area. J. Physiol. (Lond.) 245: 63-80.

Knibestöl, M., and $\AA$. B. Vallbo (1980) Intensity of sensation related to activity of slowly adapting mechanoreceptive units in the human hand. J. Physiol. (Lond.) 300: 251-267.

Kruger, L., and B. Kenton (1973) Quantitative neural and psychophysical data for cutancous mechanoreceptor function. Brain Res. 49: 124.

Marks, L. E. (1979) Summation of vibrotactile intensity: An analogue to auditory critical bands? Sensory Processes 3: 188-203.

Matthews, B. H. C. (1931) The response of a single end organ. J. Physiol. (Lond.) 71: 64-110.

Mei, J., K. P. Tuckett, D. A. Poulos, K. W. Horch, J. Y. Wei, and P. R. Burgess (1983) The neural signal for skin indentation depth. II. Steady indentations. J. Neurosci. 3: 2652-2659.

Melzack, R., and H. Eisenberg (1968) Skin sensory afterglows. Science 159: $445-447$.

Mendell, L. M., and P. D. Wall (1965) Responses of single dorsal cord 
cells to peripheral cutaneous unmyelinated fibers. Nature 206: 9799.

Molinari, H. H., J. D. Greenspan, and D. R. Kenshalo (1977) The effects of rate of temperature change and adapting temperature on thermal sensitivity. Sensory Processes 1: 354-363.

Mountcastle, V. B. (1967) The problem of sensing and the neural coding of sensory events. In The Neurosciences, G. C. Quarton, T. Melnechuk, and F. O. Schmitt, eds., pp. 393-408, Rockefeller University Press, New York.

Petit, J., and Y. Galifret (1978) Sensory coupling function and the mechanical properties of the skin. In Active Touch, G. Gordon, ed., pp. 19-27, Pergamon Press, Oxford.

Price, D. D. (1972) Characteristics of second pain and flexion reflexes indicative of prolonged central summation. Exp. Neurol. 37: 371387.

Price, D. D., R. L. Hayes, M. Ruda, and R. Dubner (1978) Spatial and temporal transformations of input to spinothalamic tract neurons and their relation to somatic sensations. J. Neurophysiol. 41: 933947.

Pubols, B. H., Jr. (1982a) Factors affecting cutaneous mechanoreceptor response. I. Constant force versus constant displacement stimulation. J. Neurophysiol. 47: 515-529.
Pubols, B. H., Jr. (1982b) Factors affecting cutaneous mechanoreceptor response. II. Changes in mechanical properties of skin with repeated stimulation. J. Neurophysiol. 47: 530-542.

Sherrington, C. S. (1900) Cutaneous sensations. In Text-Book of Physiology, E. A. Schafer, ed., Vol. 2, pp. 920-972, Macmillan, New York. Stevens, J. C., and J. D. Mack (1959) Scales of apparent force. J. Exp. Psychol. 58: 405-413.

Talbot, W. H., I. Darian-Smith, H. H. Kornhuber, and V. H. Mountcastle (1968) The sense of flutter-vibration: Comparison of the human capacity with response patterns of mechanoreceptive afferents from the monkey hand. J. Neurophysiol. 31: 301-334.

Verrillo, R. T. (1966) Vibrotactile sensitivity and the frequency response of Pacinian corpuscles. Psychon. Sci. 4: 135-136.

Verrillo, R. T. (1968) A duplex mechanism of mechanoreception. In The Skin Senses, D. R. Kenshalo, ed., pp. 139-159, Charles C Thomas, Springfield, IL.

von Békésy, G. (1958) Funneling in the nervous system and its role in loudness and sensation intensity on the skin. J. Acoust. Soc. Am. 30: 399-412.

Zigler, M. J. (1932) Pressure adaptation-time: A function of intensity and extensity. Am. J. Psychol. 44: 709-720. 